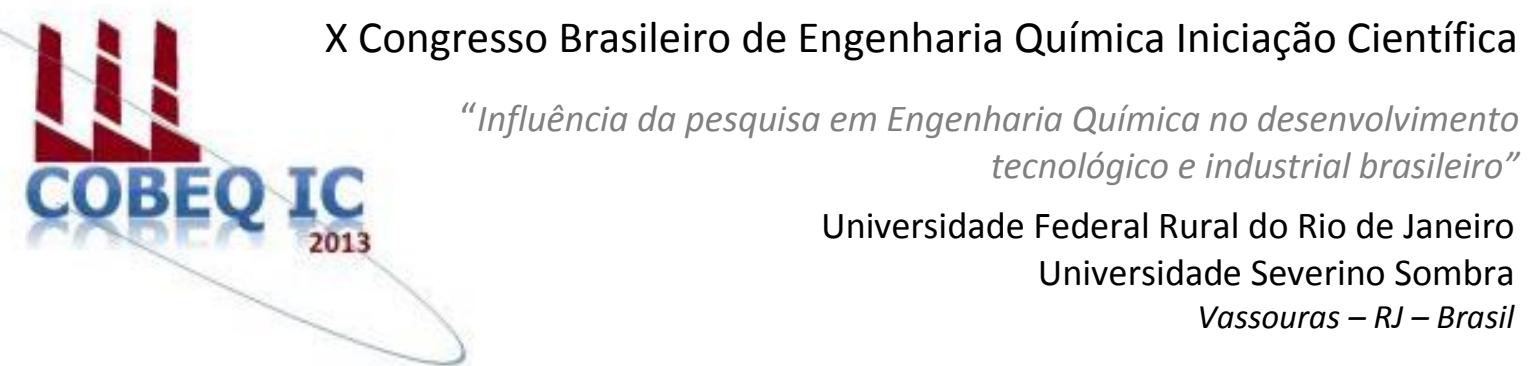

\title{
ANÁLISE DAS CARACTERÍSTICAS DE TRANSFERÊNCIA DE CALOR DO REATOR DE UM SISTEMA DE CLIMATIZAÇÃO POR ADSORÇÃO
}

\author{
RONÇANI*1 ${ }^{1}$ M.D.; GENEROSO² ${ }^{\text {, D.J.; OLIVEIRA }}{ }^{3}$, R.G. \\ ${ }^{1}$ Aluno do Campus Araranguá/UFSC ${ }^{2}$ Professor do IFSC $\quad{ }^{3}$ Professor da UFSC \\ Laboratório de Ciências Térmicas Aplicadas (Labcitea) - Campus Araranguá - Universidade \\ Federal de Santa Catarina \\ Endereço - Rua Pedro João Pereira, 150, Mato Alto - Araranguá, SC - CEP 88900-000, \\ email: rogerio.oliveira@ufsc.br
}

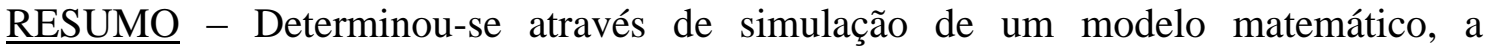
influência da distância entre aletas e da espessura do leito adsortivo do reator de um sistema de climatização por adsorção, no seu tempo de ciclo, potência de refrigeração específica (PRE) e coeficiente de desempenho (COP). O reator tem o formato de um tubo cilíndrico e contém sílica-gel como adsorvente e água como refrigerante. A troca de calor entre o reator e o fluido térmico ocorria por convecção natural, sendo que a temperatura do fluido térmico de aquecimento foi de $80{ }^{\circ} \mathrm{C}$ e de resfriamento foi de $25^{\circ} \mathrm{C}$. Os resultados indicaram que a temperatura no leito não pode ser considerada uniforme caso não haja aletas no leito ou caso haja apenas aletas axiais. Os resultados também indicaram que, quanto maiores são a distância entre aletas e a espessura do leito adsortivo, maior é o tempo de ciclo e menor é a PRE, sendo que o COP não é influenciado por esses fatores. A análise dos resultados do modelo matemático auxiliará no projeto e construção do reator para um mini sistema de refrigeração por adsorção que será utilizado para fins didáticos.
\end{abstract}

Palavras chave: modelagem, refrigeração, simulação.

\section{INTRODUÇÃO}

Com a crescente demanda por energia elétrica (EPE, 2011), as alternativas para se obter ambientes refrigerados sem a utilização da mesma podem se tornar cada vez mais atrativas. Dentre as técnicas de refrigeração cuja principal fonte energética não é a eletricidade, pode-se destacar os sistemas por adsorção. Eles podem produzir efeito frigorífico utilizando rejeito térmico de outros processos ou energia solar como fonte de energia (Oliveira, 2004).

Basicamente, pode-se montar um sistema de refrigeração por adsorção utilizando um reator e um trocador de calor, que atua como evaporador ou condensador. Nesse ciclo de refrigeração, o vapor refrigerante é comprimido termicamente por um material adsorvente ao invés de ser comprimido mecanicamente em um compressor movido por energia elétrica (Leite et al, 2012). 
Este trabalho teve por objetivo a modelagem matemática e simulação de um sistema de climatização por adsorção física, que utiliza sílica-gel como adsorvente e água como refrigerante. $\mathrm{O}$ reator simulado é um tubo cilíndrico com um canal em seu centro radial, que serve para reduzir a resistência à transferência de massa do gás refrigerante no leito adsortivo. Foi avaliada a influência do uso de aletas na uniformização da temperatura do leito adsortivo, no tempo de ciclo, na potência de refrigeração específica (PRE) e no coeficiente de desempenho (COP). Os resultados gerados pelo modelo irão subsidiar a construção de um sistema de pequeno porte para fins didáticos.

\section{MATERIAIS E MÉTODOS}

\section{Equações e Modelagem}

O reator do sistema de climatização por adsorção descrito nesse trabalho tem o formato de um tubo cilíndrico com um canal no centro radial para escoamento do fluido refrigerante. $\mathrm{O}$ leito adsortivo, portanto, tem formato anular e foi considerado o uso de aletas - radiais ou axiais - em seu interior, para melhorar a transferência de calor e uniformizar a temperatura do mesmo. A Figura 1 ilustra esquematicamente o reator com aletas radiais.

No leito adsortivo, foi utilizado sílica gel como adsorvente e água como refrigerante.

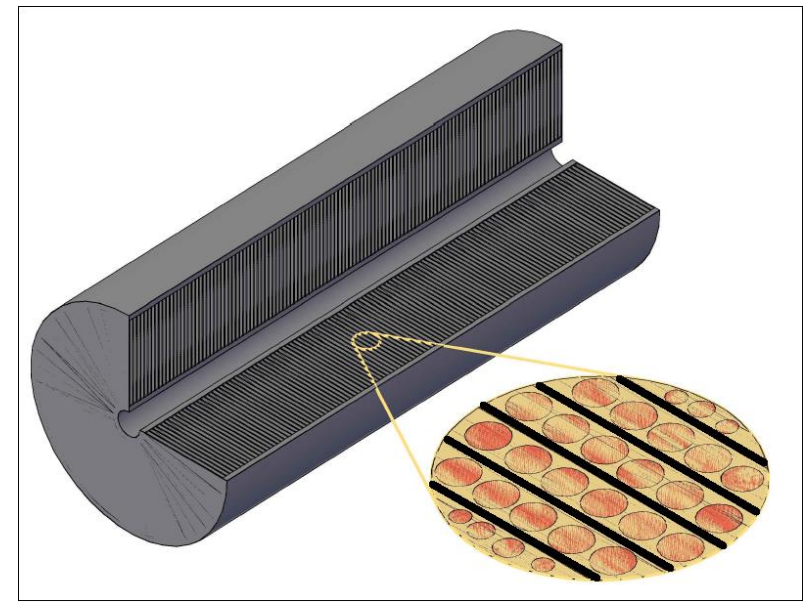

Figura 1 - Ilustração esquemática do reator.

$\mathrm{Na}$ parte externa do reator, o mesmo era aquecido, na etapa de dessorção, por água à $80^{\circ} \mathrm{C}$ e resfriado, na etapa de adsorção, por água à $25^{\circ} \mathrm{C}$. $\mathrm{O}$ coeficiente de transferência de calor por convecção natural he foi calculado pela Equação 1.

$$
h e=\frac{N u * k_{W}}{H}
$$

Onde $N u$ é o Numero de Nusselt, $k_{W}$ é a condutividade térmica da água e $H$ é o comprimento característico de $\mathrm{Nu}$, sendo considerado o diâmetro externo do reator quando o mesmo foi posicionado na horizontal e a altura do reator quando o mesmo foi posicionado na vertical. $\mathrm{O} N u$ foi calculado conforme apresentado na literatura (Incropera, 2008).

O coeficiente global de transferência de calor $U$ do fluido térmico para o leito adsortivo foi calculado pela Equação 2.

$$
U=\frac{1}{A *(R 1+R 2+R 3)}
$$

Onde $A$ é a área do conjunto de aletas mais a área da parede interna do reator, e $R l$, $R 2$ e $R 3$ representam, respectivamente, a resistência térmica entre o fluido e a parede externa do reator, a resistência de condução na parede do reator e a resistência entre a parede interna do reator e o leito adsortivo, e foram calculados pelas Equações 3, 4 e 5 .

$$
\begin{aligned}
R 1 & =\frac{1}{h e * \pi * D_{e} * L} \\
R 2 & =\frac{\log \left(D_{e} / D_{i}\right)}{2 * \pi * k_{t u b} * L} \\
R 3 & =\frac{1}{h i * \eta * A}
\end{aligned}
$$

Onde $L$ é o comprimento do reator, $D_{e}$ é o diâmetro externo e $D_{i}$ é o diâmetro interno da parede do reator, $k_{t u b}$ é a condutividade térmica da parede do reator, $h i$ é o coeficiente de transferência de calor entre a parede interna do reator e o leito adsortivo e $\eta$ é a eficiência do conjunto de aletas (Incropera, 2008).

A temperatura $T$ do reator, em função do tempo, foi calculada através do método da capacitância global, conforme Equação 6. 


$$
\begin{aligned}
T= & T_{\infty}+\left(T i-T_{\infty}\right) * e^{-a t} \\
& +\frac{b / a}{T i-T_{\infty}} *\left(1-e^{-a t}\right)
\end{aligned}
$$

Onde $T i$ é a temperatura inicial do reator, $T \infty$ é a temperatura do fluido de aquecimento ou resfriamento e $t$ é o tempo decorrido após o inicio da transferência de calor. Os coeficientes $a$ e $b$ foram calculados pelas Equações 7 e 8, respectivamente.

$$
\begin{aligned}
& a=\frac{U * A}{\rho_{s g} * V_{s g} * C p_{s g}} \\
& b=\frac{E g}{\rho_{s g} * V_{s g} * C p_{s g}}
\end{aligned}
$$

Onde $\rho_{s g}$ e $C p_{s g}$ são, respectivamente, a massa específica e o calor específico do adsorvente, $V_{s g}$ é o volume de adsorvente contido no reator e $E g$ é o termo de geração de energia associado aos processos de dessorção e adsorção (Incropera, 2008).

A condição para aplicação do método da capacitância global foi verificada pelo cálculo do Número de Biot, conforme Equação 9.

$$
B i=\frac{U * L c}{k_{s g}}
$$

Onde $L c$ é o comprimento característico do reator e $k_{s g}$ é a condutividade térmica do adsorvente. Para que se possa aplicar o método da capacitância global, o Número de Biot deve ser menor do que 0,1 (Incropera, 2008).

A potência frigorífica do sistema foi calculada pela Equação 10.

$$
P=\frac{\Delta m s g *(h v-h l)}{t c}
$$

Onde $h v$ é a entalpia de vapor saturado do adsorvato na temperatura de evaporação, $h l$ é a entalpia de líquido saturado do adsorvato na temperatura de condensação, tc é o tempo necessário para realização do ciclo e $\Delta m s g$ é a massa de adsorvato que é adsorvida pelo adsorvente, calculada pela Equação 11 .

$$
\Delta m s g=\left(X_{f}-X_{i}\right) * m_{s g}
$$

Onde $m_{s g}$ é a massa de adsorvente contida no reator, $X_{i}$ é a umidade em base seca do adsorvente no inicio da etapa de adsorção e $X_{f}$ é a umidade em base seca do adsorvente no final do processo de adsorção. A concentração de adsorvato no reator foi calculada pela Equação 12.

$$
X=\frac{K_{0} e^{\frac{\Delta_{\text {ads }} H}{R T}} P_{1}}{\left(1+\left(\left(\frac{K_{0}}{X_{m}}\right) e^{\frac{\Delta_{a d s} H}{R T}} P_{1}\right)^{t 1}\right)^{\frac{1}{t 1}}}
$$

Onde $K_{0}$ é uma constante, $\Delta_{a d s} H$ é a entalpia de adsorção, $R$ é a constante universal dos gases para o adsorvato, $T$ é a temperatura de equilíbrio do adsorvato na fase gasosa, $P_{l}$ é a pressão de equilíbrio do adsorvato na fase gasosa, $X m$ é a capacidade de adsorção nas monocamadas e $t l$ é a constante de Tóth (Chua et al, 2002).

O COP do sistema foi calculado pela Equação 13.

$$
C O P=\frac{Q r}{Q d}
$$

Onde $Q r$ é o calor retirado pelo evaporador na etapa de adsorção, calculado pela Equação 14, e $Q d$ é o calor necessário para realizar a etapa de dessorção, calculado pela Equação 15.

$$
\begin{aligned}
& Q r=\Delta m s g *(h v-h l) \\
& Q d=Q_{s g}+Q_{a l}+Q_{t u b}+Q_{a g}
\end{aligned}
$$

Onde $Q_{s g}, \quad Q_{a l}, Q_{t u b}$ e $Q_{e g}$ são, respectivamente, os calores necessários para aquecer a sílica gel, as aletas, o tubo e o refrigerante, na etapa de dessorção, e são calculados pelas Equações 16, 17, 18 e 19.

$$
\begin{aligned}
& Q_{s g}=m_{s g} * C p_{s g} *(T f-T i) \\
& Q_{a l}=m_{a l} * C p_{a l} *(T f-T i) \\
& Q_{t u b}=m_{t u b} * C p_{t u b} *(T f-T i) \\
& Q_{a g}=E g * t d s
\end{aligned}
$$


Onde $m_{s g}, \quad m_{a l}$ e $m_{t u b}$ são, respectivamente, as massas de sílica gel, aletas e do tubo, $C p_{s g}, C p_{a l}$ e $C p_{\text {tub }}$ são, respectivamente, os calores específicos da sílica gel, das aletas e do tubo, $T f$ é a temperatura no final da etapa de dessorção e $t d s$ é o tempo necessário para realização da etapa de dessorção.

\section{Ensaios e Simulações}

Foi avaliada a influência da distância entre aletas radiais no tempo de ciclo, na PRE e no COP. Nesses ensaios, a espessura do leito adsortivo foi mantida constante em $35 \mathrm{~mm}$ e a distância entre aletas foi variada entre 1 e 5,5 $\mathrm{mm}$. O raio do canal de escoamento de gás foi considerado $5 \mathrm{~mm}$. A Tabela 1 apresenta a configuração do reator para esses ensaios.

Tabela 1 - Ensaios 1 à 10.

\begin{tabular}{ccc}
\hline Ensaios & $\begin{array}{c}\text { Espessura do } \\
\text { leito }(\mathbf{m m})\end{array}$ & $\begin{array}{c}\text { Distância entre } \\
\text { aletas }(\mathbf{m m})\end{array}$ \\
\hline $\mathbf{1}$ & 35 & 1,0 \\
$\mathbf{2}$ & 35 & 1,5 \\
$\mathbf{3}$ & 35 & 2,0 \\
$\mathbf{4}$ & 35 & 2,5 \\
$\mathbf{5}$ & 35 & 3,0 \\
$\mathbf{6}$ & 35 & 3,5 \\
$\mathbf{7}$ & 35 & 4,0 \\
$\mathbf{8}$ & 35 & 4,5 \\
$\mathbf{9}$ & 35 & 5,0 \\
$\mathbf{1 0}$ & 35 & 5,5 \\
\hline
\end{tabular}

Foi avaliada também a influência da espessura do leito adsortivo no tempo de ciclo, PRE e COP. Para isso, o raio do canal de escoamento de gás foi mantido constante em 5 $\mathrm{mm}$ e foi alterado somente o raio externo. Para essa simulação, a distância entre aletas foi mantida constante em $1,5 \mathrm{~mm}$ e a espessura do leito adsortivo variou entre 15 e $60 \mathrm{~mm}$. A Tabela 2 apresenta a configuração do reator para esses ensaios.

Não foram realizados ensaios com aletas axiais, pois as mesmas não proporcionaram uniformidade na temperatura do leito adsortivo. Os ensaios de 1 a 20 foram realizados com o reator na posição horizontal e vertical, utilizando aletas radiais nos dois casos.

Tabela 2 - Ensaios 11 à 20.

\begin{tabular}{ccc}
\hline Ensaios & $\begin{array}{c}\text { Espessura do } \\
\text { leito }(\mathbf{m m})\end{array}$ & $\begin{array}{c}\text { Distância entre } \\
\text { aletas }(\mathbf{m m})\end{array}$ \\
\hline $\mathbf{1 1}$ & 15 & 1,5 \\
$\mathbf{1 2}$ & 20 & 1,5 \\
$\mathbf{1 3}$ & 25 & 1,5 \\
$\mathbf{1 4}$ & 30 & 1,5 \\
$\mathbf{1 5}$ & 35 & 1,5 \\
$\mathbf{1 6}$ & 40 & 1,5 \\
$\mathbf{1 7}$ & 45 & 1,5 \\
$\mathbf{1 8}$ & 50 & 1,5 \\
$\mathbf{1 9}$ & 55 & 1,5 \\
$\mathbf{2 0}$ & 60 & 1,5 \\
\hline
\end{tabular}

\section{RESULTADOS}

Os resultados obtidos nos ensaios de 1 a 20 com o reator na posição horizontal e vertical foram praticamente iguais. Sendo assim, aqui serão apresentados somente os resultados para a posição vertical.

A Figura 2 ilustra a variação no tempo de ciclo em função da distância entre aletas, enquanto que a Figura 3 ilustra a variação na PRE em função da distância entre aletas, resultados obtidos nos ensaios 1 a 10 .

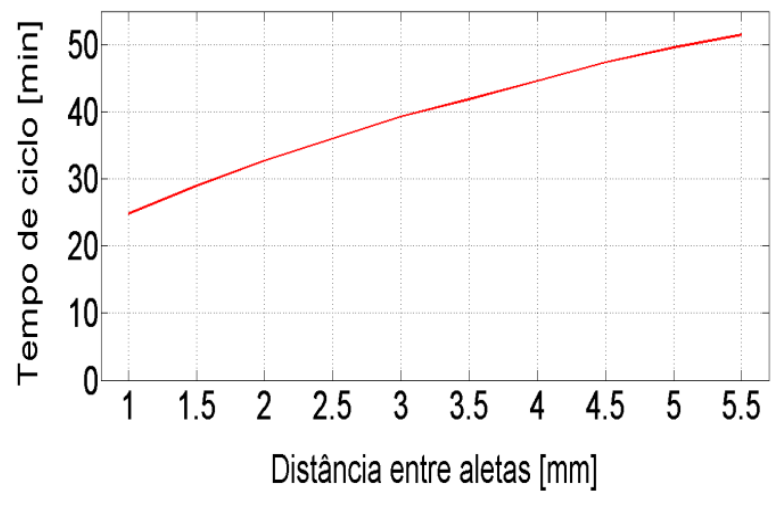

\section{Figura 2 - Variação do tempo de ciclo em função da distância entre aletas.}

Os resultados apresentados nessas figuras indicam que quanto maior a distância entre aletas, maior é o tempo de ciclo e menor é a PRE. O COP praticamente não foi influenciado pela variação da distância entre aletas e se manteve em torno de 0,70. 


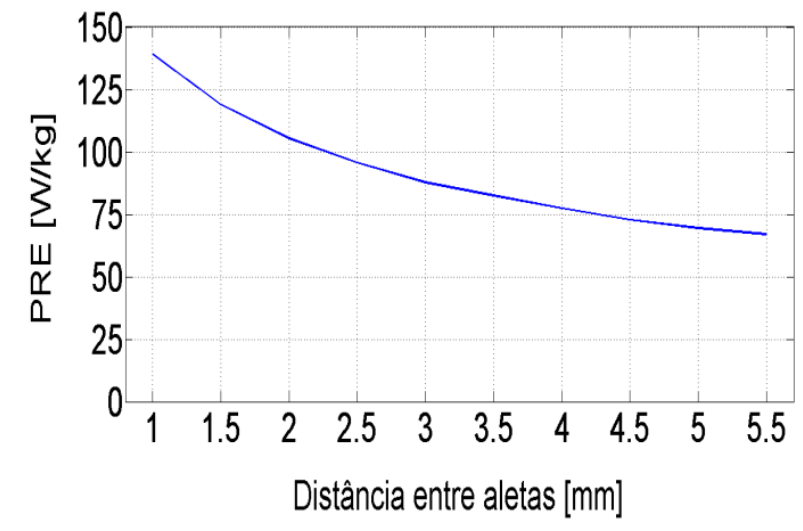

\section{Figura 3 - Variação da PRE em função da distância entre aletas.}

A Figura 4 apresenta a variação no tempo de ciclo em função da espessura do leito adsortivo, enquanto a Figura 5 apresenta a variação da PRE em função da espessura do leito adsortivo, resultados obtidos com os ensaios 11 a 20.

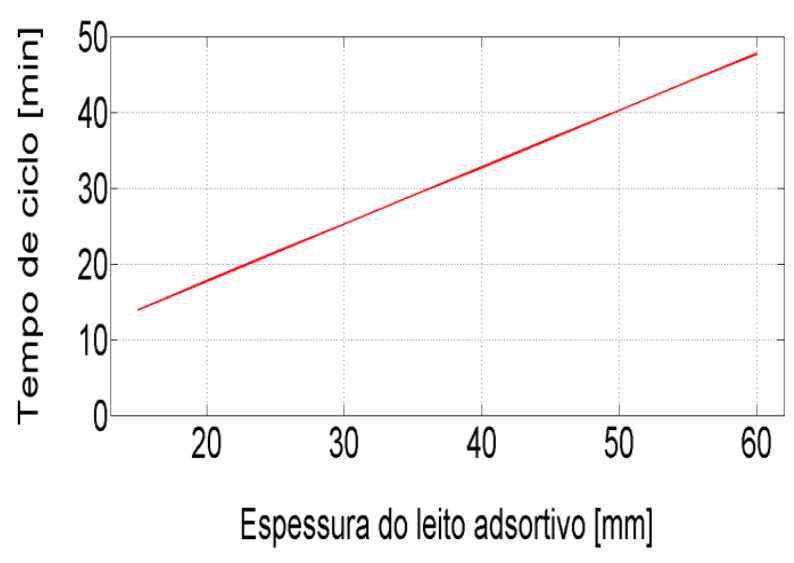

Figura 4 - Variação do tempo de ciclo em função da espessura do leito adsortivo.

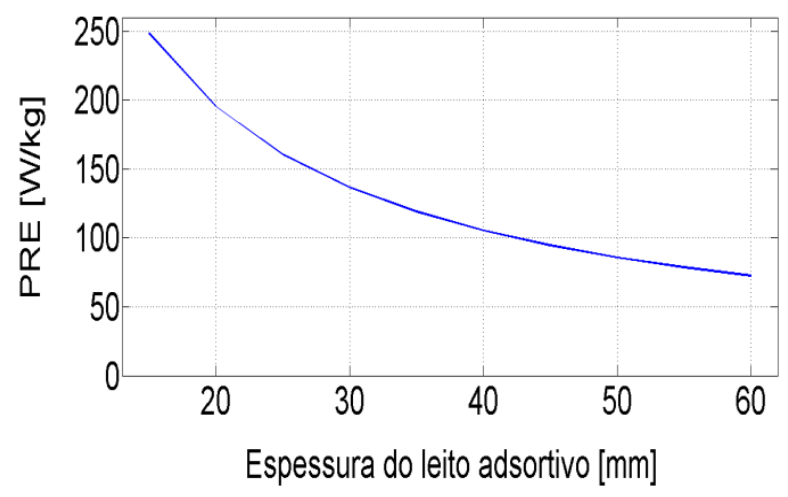

Figura 5 - Variação da PRE em função da espessura do leito adsortivo.
Os resultados apresentados nas Figuras 4 e 5 indicam que quanto maior a espessura do leito adsortivo, maior é o tempo de ciclo e menor é a PRE. O COP não foi influenciado pela variação da espessura do leito adsortivo e se manteve em torno de 0,69 .

Um sistema utilizando um reator com espessura do leito adsortivo de $35 \mathrm{~mm}$ e aletas radiais espaçadas de $1,5 \mathrm{~mm}$, utilizando água a $80{ }^{\circ} \mathrm{C}$ como fonte de calor e água a $25{ }^{\circ} \mathrm{C}$ como sumidouro de calor, pode fornecer uma potência de refrigeração específica de até 119 W por kg de sílica gel e apresentar COP de até 0,69 , operando sob um ciclo de 29 minutos.

\section{CONCLUSÃO}

Os resultados indicaram que o uso de aletas axiais não é adequado para o modelo de reator descrito, pois não propicia um aquecimento uniforme do leito adsortivo. Todavia, o uso de aletas radiais, quanto mais próximas entre si, propiciaram ao reator um menor tempo de ciclo e maior potência frigorífica por unidade de massa. Também observou-se que quanto maior a espessura do leito adsortivo, maior o tempo de ciclo e menor a potência frigorífica específica. Observou-se também que o COP praticamente não foi influenciado pela variação da distância entre aletas e pela espessura do leito adsortivo. Isso ocorreu porque a potência frigorífica aumentava ou diminuía proporcionalmente à potência de calor fornecida. Por fim, a posição horizontal ou vertical para o reator também não influenciou no tempo de ciclo, potência frigorífica e COP.

\section{NOMENCLATURA}

$A$ - área do conjunto de aletas $\left[\mathrm{m}^{2}\right]$;

$B i$ - Número de Biot;

COP - coeficiente de desempenho;

$C p$ - calor específico [J/kg.K];

$D_{e}$ - diâmetro externo do reator [m];

$D_{i}$ - diâmetro interno da parede do reator [m];

$E g$ - termo de geração de energia associado aos processos de adsorção e dessorção [W]; $H$ - comprimento característico de $\mathrm{Nu}[\mathrm{m}]$; he - coeficiente de transferência de calor por convecção natural $\left[\mathrm{W} / \mathrm{m}^{2} . \mathrm{K}\right]$; 
$h i$ - coeficiente de transferência de calor entre a parede interna do reator e o leito adsortivo $\left[\mathrm{W} / \mathrm{m}^{2} . \mathrm{K}\right]$

$h l$ - entalpia de líquido saturado do adsorvato na temperatura de condensação $[\mathrm{J} / \mathrm{kg}]$;

$h v$ - entalpia de vapor saturado do adsorvato na temperatura de evaporação $[\mathrm{J} / \mathrm{kg}]$;

$k$ - condutividade térmica [W/m.K];

$K_{0}$ - constante adimensional;

$L$ - comprimento do reator [m];

$L c$ - comprimento característico do reator $[\mathrm{m}]$;

$m$ - massa $[\mathrm{kg}]$

$N u$ - Número de Nusselt;

$P$ - potência frigorífica do sistema [W];

$P_{1}$ - pressão de equilíbrio do adsorvato na fase gasosa $[\mathrm{Pa}]$;

PRE - potência de refrigeração específica

[W/kg];

$Q$ - calor sensível [J];

$Q d$ - calor necessário para realizar a etapa de dessorção [J];

$Q_{e g}$ - calor necessário para aquecer o refrigerante na etapa de dessorção $[\mathrm{J}]$;

$X m$ - capacidade de monocamadas $[\mathrm{kg} / \mathrm{kg}]$;

$Q r$ - calor retirado pelo evaporador na etapa de adsorção $[\mathrm{J}]$;

$R$ - constante universal dos gases para o adsorvato [J/kg.K];

$t$ - tempo decorrido após o inicio da transferência de calor para o reator [s];

$T$ - temperatura instantânea do reator $[\mathrm{K}]$;

tl - constante de Tóth;

tc - tempo necessário para realização do ciclo de refrigeração $[\mathrm{s}]$;

$t d s$ - tempo necessário para realização da etapa de dessorção [s];

$T i$ - temperatura do reator no início da etapa de dessorção $[\mathrm{K}]$;

$T f$ - temperatura do reator no final da etapa de dessorção [K];

$T \infty$ - temperatura do fluido de aquecimento ou resfriamento do reator $[\mathrm{K}]$;

$U$ - coeficiente global de transferência de calor $\left[\mathrm{W} / \mathrm{m}^{2} . \mathrm{K}\right]$;

$V_{s g}$ - volume de adsorvente contido no reator $\left[\mathrm{m}^{3}\right]$;

$X$ - Umidade do adsorvente em base seca $[\mathrm{kg} / \mathrm{kg}]$

$X_{i}$ - Umidade do adsorvente em base seca no inicio da etapa de adsorção;

$X_{f}$ - Umidade do adsorvente em base seca no final do processo de adsorção.

\section{Subscritos}

al-aletas;

$s g$ - sílica gel;

tub - tubo do reator;

$W$ - água;

\section{Letras gregas}

$\Delta a d s H$ - entalpia de adsorção [J/kg];

$\Delta m s g$ - massa de adsorvato que é adsorvida no reator $[\mathrm{kg}]$;

$\eta$ - eficiência do conjunto de aletas;

$\rho_{s g}-$ massa específica do adsorvente $\left[\mathrm{kg} / \mathrm{m}^{3}\right]$.

\section{REFERÊNCIAS}

CHUA, H.T., NG, K.C., CHAKRABORTY, A., OO, N.M., OTHMAN, M.A., (2002), Adsorption Characteristics of Silica Gel + Water Systems, Journal of Chemical and Engineering Data, 47, 1177 - 1181

EPE/ONS (2011). Nota Técnica DEA 16/11: Projeção da demanda de energia elétrica para os próximos 10 anos (2012-2021). Disponível em: <http://www.epe.gov.br/m ercado/Documents/S\%C3\%A9rie\%20Estu dos\%20de\%20Energia/20120104_1.pdf>. Acesso em: 10 ago. 2013

INCROPERA, F.P., BERGMAN, T.L., DEWITT, D.P. (2008), Fundamentos de transferência de calor e de massa, $6^{\mathrm{a}}$ ed., Editora LTC, Rio de Janeiro-RJ, 643p

LEITE, G.F., SÁNCHEZ, C.J.N., RONÇANI, M.D., OLIVEIRA, R.G. (2012), "Comparação de modelos matemáticos de transferência de calor em reatores de sistemas de refrigeração por quimiosorção", Anais do Simpósio de Integração Científica e Tecnológica do Sul Catarinense, Criciúma-SC

OLIVEIRA, R.G. (2004), Avaliação de um sistema de refrigeração por adsorção para produção de gelo, operando diferentes tipos de ciclo com baixas temperaturas de geração, Departamento de Engenharia de Alimentos - Unicamp, Campinas-SP (tese de doutorado), $185 \mathrm{p}$

\section{AGRADECIMENTOS}

Ao CNPq, pela bolsa PIBIC concedida. 